\title{
INSTRUCTIONAL CONFERENCE ON DIFFERENTIAL EQUATIONS
}

to be held from 11th to $23 \mathrm{rd}$ September, 1967 in the University of Edinburgh under the auspices of

THE LONDON MATHEMATICAL SOCIETY

THE EDINBURGH MATHEMATICAL SOCIETY

and with the support of

THE NATO ADVANCED STUDY INSTITUTE

It is the aim of this Conference to serve the non-specialist as well as to offer lectures of interest to the specialist; also to interest both pure and applied mathematicians in modern developments in differential equations.

The first week of the Conference will be devoted to an introductory programme consisting of the following courses, of 6 hours each:

Hilbert Spaces and Ordinary Differential Equations, by

Dr. J.B. McLeod and Professor W.N. Everitt.

Functional Analysis and Theory of Distributions, by

Professor J.R. Ringrose and Professor A.P. Robertson.

Introduction to the Navier-Stokes Equation and Allied Results, by Mr. L.E. Fraenkel and Dr. D.E. Edmunds.

The following advanced full length courses will take place after completion of the introductory programme:

Generalised Sturm-Liouville Theory, by

Professor E.A. Coddington.

Partial Differential Equations with Constant Coefficients, by Professor J.F. Treves.

On the Navier-Stokes Equations, by Professor James Serrin.

There will also be a number of invited lectures on special topics to supplement the full length courses.

Early registration is advised at which time a deposit of 16 should be paid. For further particulars and for registration forms, please write to Dr. J.L. Mott, The Mathematical Institute, 20 Chambers Street, Edinburgh, Scotland marking the envelope "Instructional Conference". 